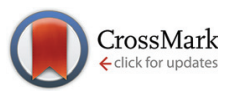

Cite this: Dalton Trans., 2016, 45, 134

\title{
Surface induces different crystal structures in a room temperature switchable spin crossover compound $\uparrow$
}

\author{
Denis Gentili, ${ }^{a}$ Fabiola Liscio, ${ }^{b}$ Nicola Demitri, ${ }^{c}$ Bernhard Schäfer, ${ }^{d}$ \\ Francesco Borgatti, ${ }^{a}$ Piero Torelli, ${ }^{e}$ Benoit Gobaut, ${ }^{\mathrm{C}}$ Giancarlo Panaccione, ${ }^{\mathrm{e}}$ \\ Giorgio Rossi, ${ }^{\text {e,f }}$ Alessandra Degli Esposti, ${ }^{9}$ Massimo Gazzano, ${ }^{9}$ Silvia Milita, ${ }^{\text {b }}$ \\ Ilaria Bergenti, ${ }^{a}$ Giampiero Ruani, ${ }^{a}$ Ivan Šalitroš, ${ }^{\text {h }}$ Mario Ruben ${ }^{\mathrm{d}, \mathrm{i}}$ and \\ Massimiliano Cavallini*a
}

\begin{abstract}
We investigated the influence of surfaces in the formation of different crystal structures of a spin crossover compound, namely $\left[\mathrm{Fe}(\mathrm{L})_{2}\right](\mathrm{LH}$ : (2-(pyrazol-1-yl)-6-(1H-tetrazol-5-yl)pyridine), which is a neutral compound thermally switchable around room temperature. We observed that the surface induces the formation of two different crystal structures, which exhibit opposite spin transitions, i.e. on heating them up to the transition temperature, one polymorph switches from high spin to low spin and the second polymorph switches irreversibly from low spin to high spin. We attributed this inversion to the presence of water molecules $\mathrm{H}$-bonded to the complex tetrazolyl moieties in the crystals. Thin deposits were investigated by means of polarized optical microscopy, atomic force microscopy, X-ray diffraction, X-ray absorption spectroscopy and micro Raman spectroscopy; moreover the analysis of the Raman spectra and the interpretation of spin inversion were supported by DFT calculations.
\end{abstract}

Received 23rd September 2015, Accepted 2nd November 2015 DOI: $10.1039 / \mathrm{c} 5 \mathrm{dt} 03712 \mathrm{c}$ www.rsc.org/dalton dramatically differ in their functional properties and behavior. ${ }^{1-5}$ This setback, which manifests itself in phenomena such as polymorphism and solvatomorphism, is particularly relevant in the drug industry; however, it is common in many materials, such as organic semiconductors, ${ }^{6,7}$ supramolecular systems ${ }^{1}$ and spin crossover (SCO) compounds., ${ }^{5-20}$ Despite some exceptions, in which polymorphism is exploited as an advantageous property, ${ }^{21-24}$ usually it is thought to be a drawback for many technological applications, which often compromises the development of materials. On the contrary, gaining a detailed knowledge of different crystal forms and their influence on the functionalities can be the manner to select the best performing phase. The growth of crystals in different structures and/or polymorphs is influenced by external parameters such as the solvent, concentration, and temperature, but it is also influenced by interfaces and surfaces. $^{25,26}$ Some of these parameters are cooperative and not independent of each other, making the control of the full set very difficult.

Here we investigated the influence of the surface on the formation of different crystal structures in a room temperature switchable SCO compound. We observed that under some conditions, the surface induces the formation of, at least, two different types of crystals, which exhibit opposite spin tran- 
sition properties, i.e. on heating the first type of crystals up to its transition temperature, it switches from the high spin to low spin state, while the second type switches from the low spin to high spin state.

SCO compounds are largely studied switchable transition metal complexes capable of switching their spin state as well as their colour, conductivity, dielectric constant, diffraction index, and mechanical properties. ${ }^{28-33}$ Since the switching conditions critically depend on the local molecular environment (e.g. packing, counter anions and/or solvent molecules, if included in the crystalline structures, etc.), the crystal structure have a crucial impact on SCO properties. ${ }^{5}$ SCO compounds are processable by conventional ${ }^{34}$ or unconventional methods ${ }^{35-38}$ and were proposed for several applications ranging from permanent/rewritable information storage and spintronic $^{27,39-41}$ to chemical actuators, ${ }^{42}$ multimodal sensors $^{43}$ of chemicals ${ }^{44,45}$ and pressure sensors. ${ }^{46}$ Several exhaustive reviews encompass the synthesis, properties and applications of SCO compounds. ${ }^{29,44,47-50}$

Here we studied SCO complex 1, whose molecular formula is $\left[\mathrm{Fe}(\mathrm{L})_{2}\right]$ (LH: (2-(pyrazol-1-yl)-6-(1H-tetrazol-5-yl)pyridine) (see the structure in Fig. 1). 1 is a neutral compound switchable around room temperature whose synthesis and characterization are reported elsewhere. ${ }^{43,51}$

As a SCO compound, based on $\mathrm{Fe}^{\mathrm{II}}, \mathbf{1}$ is particularly interesting since the spin transition occurs from a diamagnetic state (low spin state, LS, in the singlet state) in which six elec-

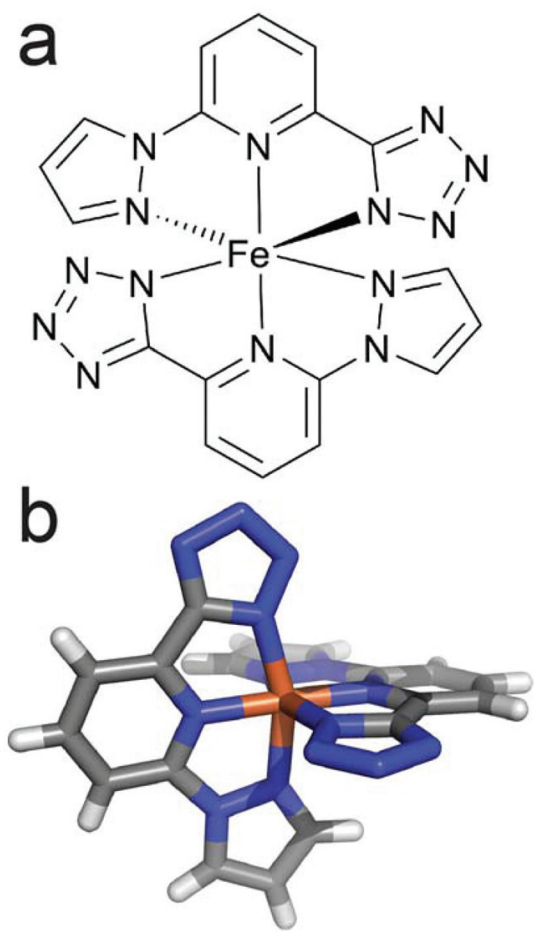

Fig. 1 (a) Chemical structure of $\left[\mathrm{Fe}(\mathrm{L})_{2}\right]$ (LH: (2-(pyrazol-1-yl)-6-(1Htetrazol-5-yl)pyridine) (1); (b) molecular structure of 1 in the low spin state.

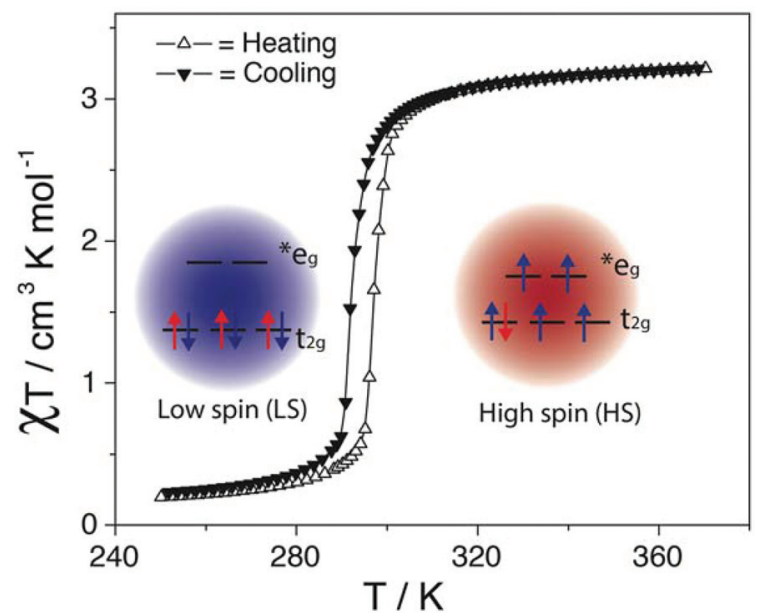

Fig. 2 Magnetic characterization and the corresponding spin state of 1.

trons of the d-level are paired in three $t_{2 g}$ orbitals to a paramagnetic state (high spin state, HS, in the quintuplet state) in which four electrons are unpaired and distributed between $t_{2 g}$ and ${ }^{*} e_{g}$ orbitals (Fig. 2). Moreover, 1 has been proved to be an efficient processable material for multimodal sensing for methanol and ethanol. ${ }^{43}$

Thin deposits of $\mathbf{1}$ were grown by drop-casting on several technologically relevant surfaces such as silicon and gold and processed by unconventional lithography. Thin deposits were investigated by means of polarized optical microscopy (POM), atomic force microscopy (AFM), X-ray diffraction (XRD), X-ray absorption spectroscopy (XAS) and micro Raman spectroscopy ( $\mu$-Raman). Moreover, since we systematically used Raman spectroscopy as a technique to establish the spin state in single crystallites, a detailed interpretation of the significant features observed in the Raman spectra was performed by using Density Functional Theory (DFT) calculations. ${ }^{52-54}$

\section{Results and discussion}

\subsection{Material characterization (bulk)}

A detailed characterization of bulk material is reported in ref. 51 and 43 . Briefly, 1 crystallizes forming block shaped crystals with $C 2 / c$ monoclinic symmetry. The unit cell contains eight complex units $\left[\mathrm{Fe}(\mathrm{L})_{2}\right]$ packed to fill $\sim 85 \%$ of the volume. The remaining voids are arranged in channels, aligned with the crystallographic $c$ axis, and filled with solvent molecules. ${ }^{51}$ As previously reported, crystals' spin state is closely connected to the temperature and solvation state of crystal cavities. ${ }^{43}$ At room temperature, crystals grown from a methanol-dichloromethane solution are yellow in the mother liquor $\left(\mathrm{CH}_{3} \mathrm{OH} /\right.$ $\mathrm{CH}_{2} \mathrm{Cl}_{2}$ ) and turn red when dried due to changes in solvent content. Structural characterization of 1 at $293 \mathrm{~K}$ shows the coordination sphere bond lengths of a low spin iron complex ${ }^{51}$ and exhibits a transition temperature from LS to HS at $295 \mathrm{~K}$ 
with a small hysteresis of $5 \mathrm{~K}$ that appears after the first thermal cycle (Fig. 2).

The powder of $\mathbf{1}$ is formed by red crystallites (mean size: $1<$ size $<100 \mu \mathrm{m}$ ) that turn yellow/orange when heated up to the transition temperature. The transition can be followed by POM observing both the change of colour and birefringence (the LS state does not show birefringence while the HS state shows a high birefringence), by XAS and by Raman spectroscopy, which shows clear features associated with a spin transition. The transition occurs in a few tens of seconds and despite the fragmentation, it is reversible, i.e. on cooling back the sample below the transition temperature the (fragmented) crystals return to red colour and lose the birefringence.

The spin transition LS $\rightarrow$ HS is concomitant with the fragmentation of the crystals while no effect on the morphology was observed during the reverse transition cooling down the crystals (i.e. HS $\rightarrow$ LS). It must be noted that the powder of $\mathbf{1}$ contains a small percentage (we estimated as $<2 \%$ ) of crystallites, which do not exhibit the spin transition. A detailed characterization of these crystallites, here named I, is reported in the ESI. $\dagger$

The Raman spectra (Fig. 3) recorded at two different temperatures, i.e. $280 \mathrm{~K}$ and $328 \mathrm{~K}$, which correspond to LS and HS respectively, show substantial differences in frequencies and intensities, indicating that the spin-state switching occurred. Particularly meaningful for the spin state discrimination of the complex are the absorptions observed for the pair of transitions recorded at 666 and $1012 \mathrm{~cm}^{-1}$ at $328 \mathrm{~K}$, which are more intense and shifted at lower frequencies than those observed at $280 \mathrm{~K}$ at 680 and $1037 \mathrm{~cm}^{-1}$. Many more features, particularly those at low frequency, support the occurrence of the spin-state transition, mainly showing a shift of their frequency. They are all of much lower intensity than those observed at higher frequency, where the main spectral change is the decrease of the intensity at high temperature.

To gain insight into the origin of the observed features in the Raman spectra, they were calculated by means of DFT

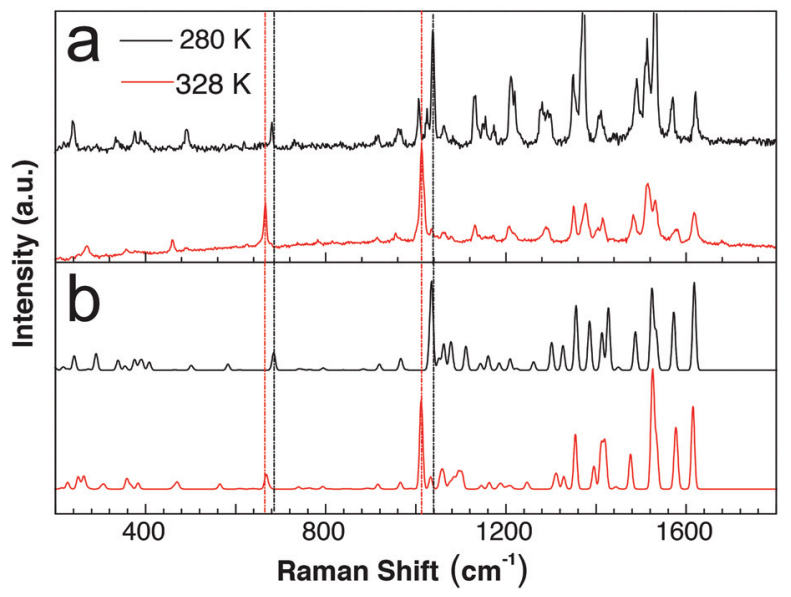

Fig. 3 Comparison between (a) the experimental and (b) simulated Raman spectra of 1. calculations for the isolated complex (see details in Experimental section 4.2). The calculated spectra of the LS and HS states were afterwards scaled to improve the comparison with the experimental spectra. The simulated spectra nicely compare with the experimental ones, paving the way for an accurate characterization of the vibrational modes, which evidence the spin-state transition. It turns out that the abovementioned significant peaks all originate from vibrations localized at the Fepyridyl units. Those at low frequency, i.e. $680 \mathrm{~cm}^{-1}(280 \mathrm{~K})$ and $666 \mathrm{~cm}^{-1}(328 \mathrm{~K})$, are largely characterized by the in-phase $\mathrm{Fe}-\mathrm{N}$ stretching mode of both pyridyl rings in the singlet state $\left(\nu^{\mathrm{LS}}=\right.$ $684 \mathrm{~cm}^{-1}$ ), which besides cause large deformations of their internal planar angles. The same kind of vibrational mode characterizes also the absorption in the HS state $\left(\nu^{\mathrm{HS}}=\right.$ $668 \mathrm{~cm}^{-1}$ ), with the prevailing contribution of one pyridyl unit to the description of this vibration. The situation is reversed for the other two absorptions at $1037 \mathrm{~cm}^{-1}(280 \mathrm{~K})$ and $1012 \mathrm{~cm}^{-1}$ (328 K) since, in this case, the bending modes of both pyridyl units induce as well a significant contribution by the $\mathrm{Fe}-\mathrm{N}$ stretching modes, as shown by the calculated $\nu^{\mathrm{LS}}=1035 \mathrm{~cm}^{-1}$ and $\nu^{\mathrm{HS}}=1011 \mathrm{~cm}^{-1}$ normal modes of the LS and HS states, respectively. The other weak features detected below $600 \mathrm{~cm}^{-1}$ in the Raman spectra originate from vibrational modes involving $\mathrm{Fe}^{\mathrm{II}}$, together with torsional modes of the connected rings.

The most intense of these absorptions are largely characterized by the stretching modes of Fe-pyridyl bonds such as those at 490 and $237 \mathrm{~cm}^{-1}(280 \mathrm{~K})$ and 460 and $270 \mathrm{~cm}^{-1}$ $(328 \mathrm{~K})$. In the frequency range above $1100 \mathrm{~cm}^{-1}$ the bending modes of the ligands give rise to transitions within the ranges 1110-1190 $\mathrm{cm}^{-1}$ and 1207-1230 $\mathrm{cm}^{-1}$, while the $\mathrm{N}-\mathrm{Fe}-\mathrm{N}$ bending modes are manifested between 1240 and $1349 \mathrm{~cm}^{-1}$, and the $\mathrm{N}-\mathrm{N}$ stretching modes of the pyrazole ring largely characterize transitions between 1280 and $1293 \mathrm{~cm}^{-1}$. The $\mathrm{C}-\mathrm{C}$ and $\mathrm{C}-\mathrm{N}$ stretching, along with the $\mathrm{C}-\mathrm{CH}$ bending modes of the rings, give rise to the observed transitions starting from $1370 \mathrm{~cm}^{-1}$ with the stretching vibrations of the pyridyl rings assigned to the high frequency absorption at 1620 and $1570 \mathrm{~cm}^{-1}(280 \mathrm{~K})$, and at 1617 and $1580 \mathrm{~cm}^{-1}(328 \mathrm{~K})$.

It is interesting to point out that, within the adopted isolated molecule model used to simulate the Raman spectra of 1, the HS state is calculated to be more stable than the LS state. The same situation occurs when it is considered in $\mathrm{CH}_{3} \mathrm{OH}$ or $\mathrm{CH}_{2} \mathrm{Cl}$ solutions. This behaviour is confirmed by the colour of the solution and the crystals in the presence of the solvent (Fig. 4a-e). On the contrary, the LS state is largely stabilized in the crystalline geometry of $\mathbf{1}$.

Other factors contribute to tune the relative energy gap between the two states, ${ }^{55,56}$ besides the modelled structures and environments, ${ }^{57}$ such as the temperature, which affects the zero-point energy (ZPE) correction to the calculated electronic energy. ${ }^{58}$ Moreover, possible interactions with absorbed polar protic solvents within the crystal can significantly influence the relative stability of the two spin-states. This is shown by calculations which consider a water molecule $\mathrm{H}$-bonded to one tetrazolyl unit of a single molecule of $\mathbf{1}$ taken in the X-ray geometry. 


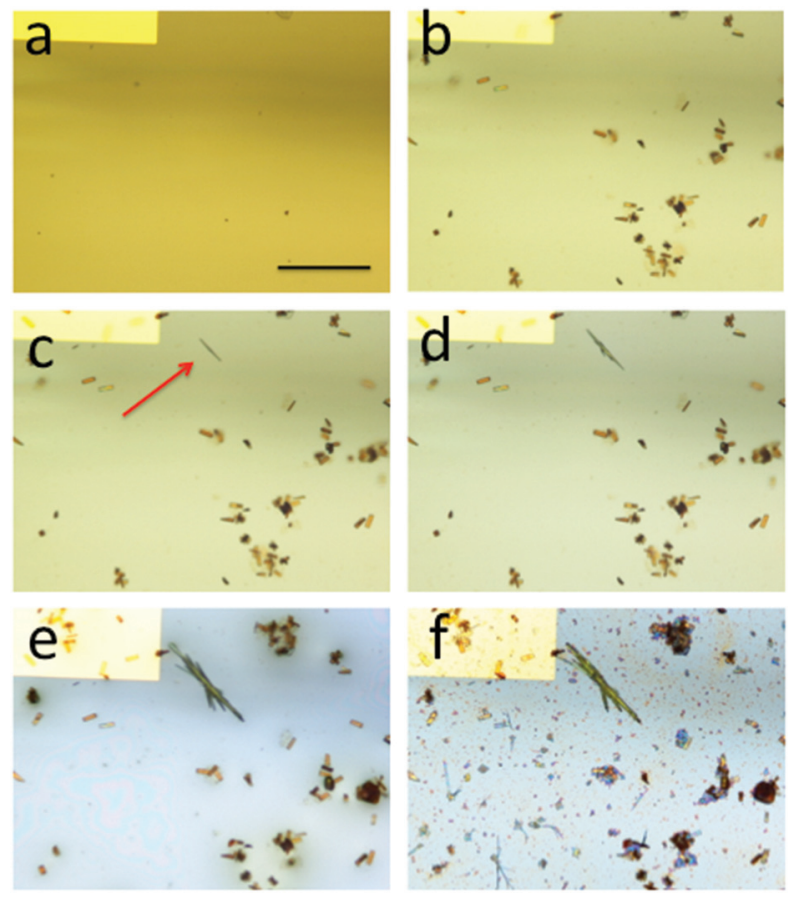

Fig. 4 Formation of polymorphic deposits of 1 on a silicon surface; a pad made of gold was used as the reference. (a) The as deposited solution. (b) Formation of block shaped crystals $\mathbf{R}$ in solution. (c) Nucleation of elongated crystals $Y$. (d) Growth of $Y$ pinned crystals. (e) The last step of solvent evaporation. ( $f$ ) Dried thin deposits showing both $R$ and $Y$ crystals. The bar in (a) is $100 \mu \mathrm{m}$

The reason why the tetrazolyl unit is particularly prone to form $\mathrm{H}$-bonds is evidenced by the natural charge analysis ${ }^{59,60}$ indicating that a large amount of electron charge $\left(\delta^{\mathrm{LS}}=-0.49 q\right.$ and $\delta^{\mathrm{HS}}=-0.59 q$ ) is localized at this unit of the ligand. Moreover, it evidences that the electron charge flows from the metal atom towards the ligands when passing from LS to HS and the other way around (see the ESI $\dagger$ ).

\subsection{Thin deposits}

Thin deposits of 1 were prepared from a $\mathrm{CH}_{3} \mathrm{OH}: \mathrm{CH}_{2} \mathrm{Cl}_{2} 1: 1$ $(\mathrm{v} / \mathrm{v})$ solution by drop-casting in solvent saturated environments and controlled temperature on $\mathrm{Si} / \mathrm{SiO}_{2}$ and $\mathrm{Au}$ substrates (for details see the Experimental section).

Fig. 4 shows the real time monitoring of the thin deposit growth.

When the deposited solution reaches supersaturation, a first type of crystals (here named $\mathbf{R}$ ) start to nucleate in solution. These crystals are the same observed in the powder. They consist of block shaped crystallites floating inside the liquid film (Fig. 4a). When the crystallites reach a critical dimension, they start to remain fixed at the surface (Fig. 4b). No evidence of other kinds of crystals was observed at this stage.

On the other hand, when only a thin film of solution remains on the surface, a second type of crystallite (here named Y) starts to form on the surface. Y crystallites consist of elongated crystals pinned at the surface that grow til complete solvent evaporation (Fig. 4c-f). Y crystallites were never observed in the powder. For both types of crystals the mean size depends on the solution shrinking rate and range between a few microns when the film was prepared in air at room temperature to $>200 \mu \mathrm{m}$ when prepared under a solvent saturated atmosphere at $277 \mathrm{~K}$. The relative percentage of the two types of crystals range from $10 \%$ to $90 \%$ and cannot be systematically controlled based on:

(i) different shrinking rates. Thin deposits were prepared under a solvent saturated atmosphere, in air and under low vacuum, changing the evaporation rate from a few tens of seconds to some hours.

(ii) Different temperatures of the substrates. We tested deposition in air in a range of temperatures from 280 to $330 \mathrm{~K}$.

(iii) Different solvent compositions. We tested the deposition from a $\left(\mathrm{CH}_{2} \mathrm{Cl}_{2}: \mathrm{CH}_{3} \mathrm{OH}\right)$ mixture ranging in composition from $1: 4$ to $4: 1(\mathrm{v} / \mathrm{v})$.

Although we cannot exclude some kinetic effects, these pieces of experimental evidence allow us to consider these effects as negligible with respect to the role of the surface.

While the solvent is present both types of crystals appear yellow; however, after complete solvent evaporation, $\mathbf{R}$ crystals turn red (Fig. 4f), as happens in the powder, while $\mathbf{Y}$ crystals remain yellow.

The crystalline structure of $\mathbf{R}$ corresponds to the crystal structure observed in the powder and is described in section 2.1.

On the other hand, the $\mathbf{Y}$ crystals tend to form large irregular aggregates, which often contain also small "red inclusions" at the centre. In contrast to the $\mathbf{R}$ crystals, the $\mathbf{Y}$ crystals exhibit a strong birefringence whose colour depends on the local thickness. Remarkably, the behaviour at POM is quite similar to the $\mathbf{R}$ crystals in the HS state. The smaller crystals (indicatively size $<5 \mu \mathrm{m}$ ) behave as single crystals (i.e. all the crystals extinguish at the same polarizer orientation), while the larger crystals are formed by different domains, randomly oriented. This strong birefringence allows us to distinguish between the two different crystals also in very small crystals (size $<2-3 \mu \mathrm{m}$ ) that look almost colourless and have ambiguous shape in optical microscopy (Fig. 5).

On heating $\mathbf{Y}$ crystals up to $296 \mathrm{~K}$ (viz. 2 K degree before the transition in the powder) or upon a strong thermal stress (i.e. temperature variation $>20 \mathrm{~K} \mathrm{~min}^{-1}$ on both heating and cooling the samples) under an air or nitrogen atmosphere, the Y crystals abruptly turn irreversibly to red and fragment. Surprisingly, the transition was not always observed upon heating (cooling) of the sample under high vacuum in the range 200-330 K with a heating (cooling) rate $<2 \mathrm{~K} \mathrm{~min}^{-1}$. We speculate that on heating the samples slowly, the $\mathbf{Y}$ crystals are preserved in a metastable phase; however this behaviour in not yet fully understood and is still under investigation. The former crystals show the same colour and birefringence of the R polymorph in the LS state, but do not show any further transition in the range of temperatures 166-400 K. Fig. 5 shows optical micrographs of a thin film when heated from room temperature to $296 \mathrm{~K}$. 


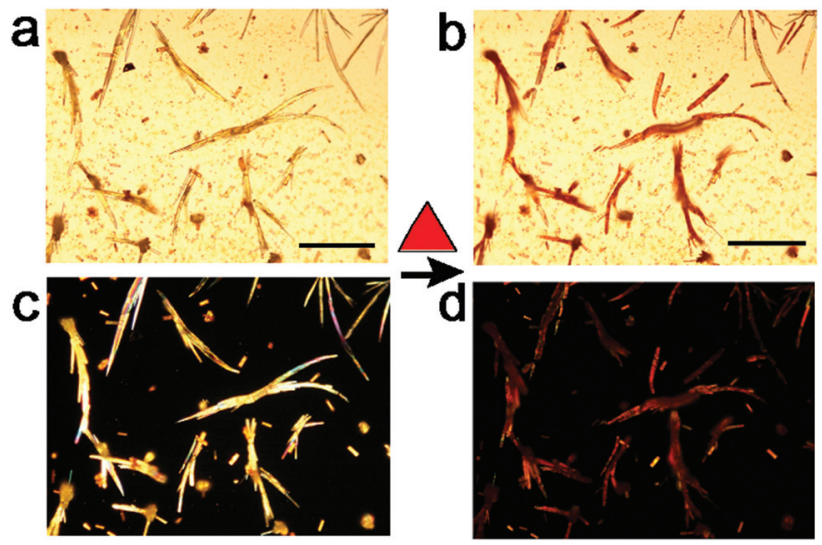

Fig. 5 (a) Optical micrograph of dropcast thin deposits of 1 in a selected zone rich in $\mathrm{Y}$ polymorphs on silicon from a $\mathrm{CH}_{3} \mathrm{OH}: \mathrm{CH}_{2} \mathrm{Cl}_{2}$ $1: 1$ solution recorded at $290 \mathrm{~K}$ and (b) the corresponding zone recorded after the thermal cycle at $300 \mathrm{~K}$. (c) The corresponding image of (a) recorded with crossed polars. (d) The corresponding image of (b) recorded with crossed polars. Bars are $100 \mu \mathrm{m}$.

The spin state of both crystals was investigated by $\mu$-Raman spectroscopy. Our set-up allows the detection of the spectra of single crystallites thanks to a laser spot size of $<1.5 \mu \mathrm{m}$. Raman spectra were collected below (at $280 \mathrm{~K}$ ) and above (at $328 \mathrm{~K}$ ) the transition temperature for both crystals. Noticeably, spectra recorded for $\mathrm{R}$ crystals correspond to the spectra of the powder within a tolerance of $\sim 1 \mathrm{~cm}^{-1}$. This characteristic was confirmed both for the LS state (i.e. at temperatures $<295 \mathrm{~K}$ ) and for the HS state (i.e. at temperatures $>298 \mathrm{~K}$, Fig. 6).

Surprisingly, the spectra of $\mathbf{Y}$ crystals are almost identical to the corresponding spectra of $\mathbf{R}$ crystals but inverted with respect to the spin state, i.e. the spectra of $\mathbf{Y}$ crystals recorded

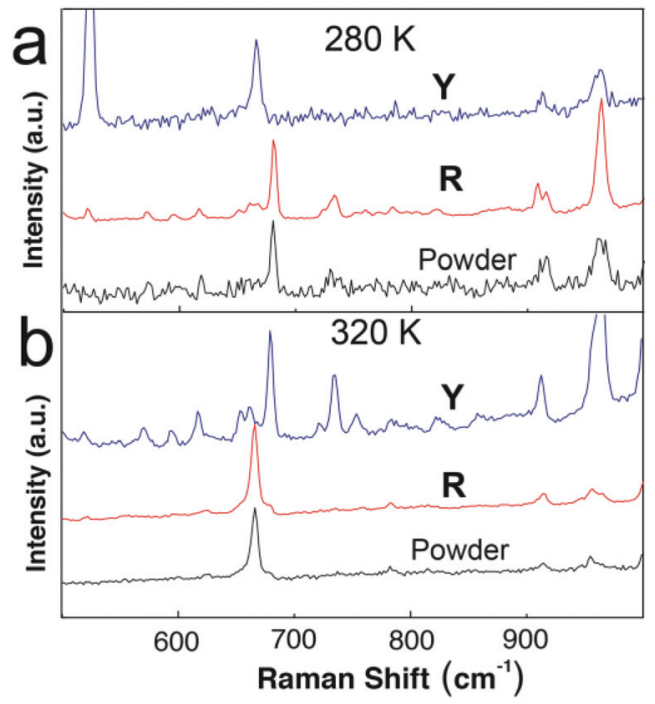

Fig. 6 Raman spectra collected at $320 \mathrm{~K}$ and $280 \mathrm{~K}$ on R and Y polymorphs compared with the powder. below the transition temperature are equal to the Raman spectra of $\mathbf{R}$ crystals recorded in the HS state while the spectra of $\mathbf{R}$ recorded above the transition temperature are equal to the Raman spectra of $\mathbf{Y}$ crystals recorded in the LS state. Considering the DFT calculations, this different spin state behaviour for the $\mathbf{Y}$ crystals could be ascribed to the presence of water or solvent $\left(\mathrm{CH}_{3} \mathrm{OH}\right)$ molecules in the structure. Fig. 6 shows a comparison of the spectra of the different crystals recorded as a function of the temperature in the range of frequencies containing the most significant, diagnostic, vibrational modes.

This indication suggests that the structure of the $\mathbf{Y}$ polymorph stabilizes the material in the HS state.

While single crystals of $\mathbf{R}$ crystals have been manually removed from the substrate in order to individually characterize them, the same procedure was not applicable to $\mathbf{Y}$ crystals because of their fragility. Therefore, structural characterization was carried out by performing XRD measurements directly on thin deposits containing $\sim 90 \%$ of a type of crystal. A specular scan of the deposit rich in $\mathbf{R}$ crystals (Fig. 7a) shows the presence of two crystal phases, of which the majority one corresponds to the structure of the powder (red squares) and the minority to the structure of the inert crystals I (green squares) observed in the powder (see the ESI $\dagger$ ). A specular scan performed on a deposit rich in $\mathbf{Y}$ crystals is characterized by reflection coming from the structure of the I crystals and a new one which can be attributed to the $\mathbf{Y}$ crystals (yellow dots). Interestingly, the $\mathbf{Y}$ crystals undergo an irreversible transition once heated up to $296 \mathrm{~K}$, in contrast to $\mathbf{R}$ crystals, in which the structure and spin state are preserved upon thermal cycling. ${ }^{43}$ Indeed, Fig. 7b shows the disappearance of reflection peaks coming from the structure $\mathbf{Y}$ in favour of a new peak at higher angle after a thermal treatment at $328 \mathrm{~K}$ (orange dots), which remains stable after cooling down to $290 \mathrm{~K}$. In the meantime, I-crystals preserve their structure regardless of the thermal treatment.

The electronic structure of the $\mathrm{Fe}^{\mathrm{II}}$ ions of complex 1 has been probed through soft X-ray Absorption Spectroscopy (XAS) at the $\mathrm{FeL}_{2,3}$ absorption edges for a sample containing $~ 70 \%$ of the $\mathbf{Y}$ polymorph (estimated value from optical images spread over a gold polycrystalline substrate). The $\mathrm{FeL}_{2,3}$ XAS spectra are very sensitive to the configuration of the $3 \mathrm{~d}$ states, thus providing direct insight into the changes occurring when passing from the low to high spin conditions. ${ }^{61}$ The XAS results shown in Fig. 8 were recorded cycling the sample temperature below and above the transition temperature of $\mathbf{1}$ $(\sim 295 \mathrm{~K})$. All of them are quite broad and featureless; however the presence of a double peak structure for the $\mathrm{L}_{3}$ edge is clearly indicative of the coexistence of different Fe states. The energy split between the peaks is about $1.6 \mathrm{eV}$, in close agreement with similar shifts of the $\mathrm{L}_{3}$ peak position observed for other SCO complexes passing from LS to HS states through temperature- or light-induced transitions. ${ }^{62,63}$ According to the literature, the low(high) energy $\mathrm{L}_{3}$ peak is assigned to the HS (LS) state, therefore suggesting that both molecules with HS or LS $\mathrm{Fe}^{\mathrm{II}}$ configurations presently occur in this range of 

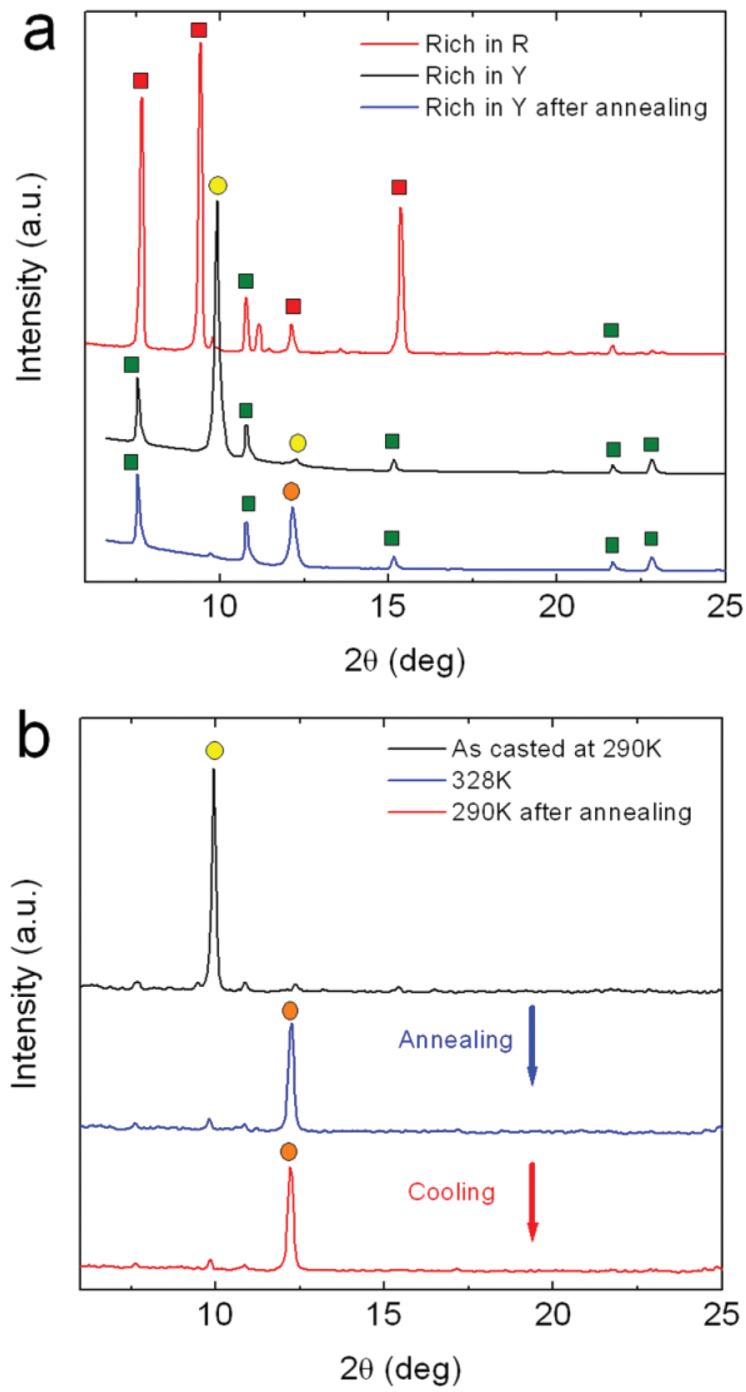

Fig. 7 (a) XRD patterns (specular scans) of dropcast deposits having a majority of block-shaped red crystals (red line) and yellow needles dropcast on silicon before (black line) and after (blue line) thermal annealing at $320 \mathrm{~K}$. Red and green squares label the reflections coming from structures $\mathbf{R}$ and $\mathrm{I}$, whereas the yellow and orange dots label the reflections coming from structure $Y$ before and after thermal treatment, respectively. (b) In situ and real time XRD patterns collected on dropcast deposits rich in yellow needles at $290 \mathrm{~K}$ (black line), $328 \mathrm{~K}$ (blue line) and after cooling down at $290 \mathrm{~K}$ (red line).

temperatures. The assignment is supported by the reversible change of intensity for these peak features when passing across the critical temperature of the SCO complex (about $295 \mathrm{~K}$ ), which is indicative of the spin-crossover behaviour although it seems to involve just a fraction of the molecules. However, because of the sample preparation procedure, we cannot exclude the possibility that other contributions to the spectra, related to surface contamination of the crystallites due to air exposure or to the presence of fragmented molecules, may overlap with the HS/LS terms, thus reducing the strength of the spectral change.

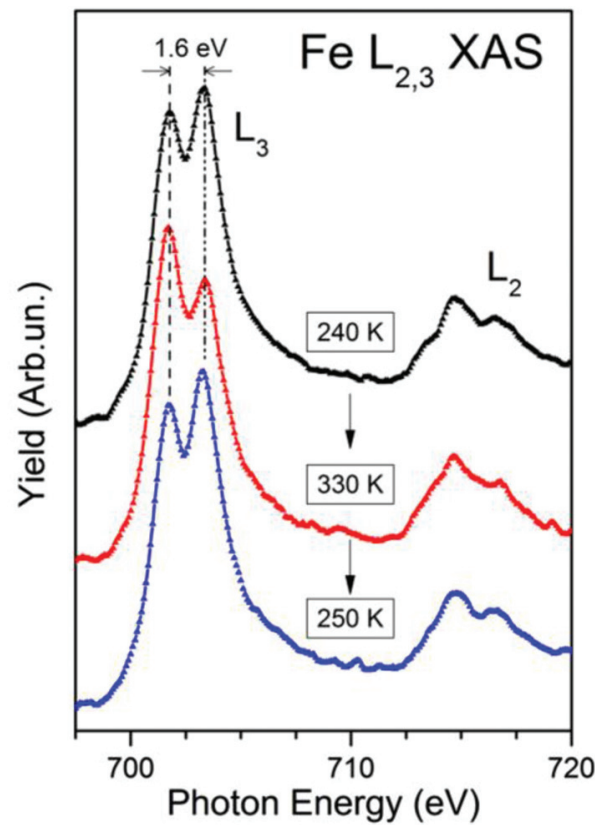

Fig. $8 \mathrm{FeL}_{2,3}$ edges for the $\mathrm{Fe}($ II) ions of complex 1 . All the spectra were normalized to the maximum intensity of the $L_{3}$ edge and vertically shifted for better comparison. The two maxima split by $1.6 \mathrm{eV}$ suggest the coexistence of high (left) and low (right) spin configurations for the $3 \mathrm{~d}$ levels. The reversible change of intensity for the main peak features when passing across the critical temperature of the SCO complex (about $295 \mathrm{~K}$ ) is indicative of the spin-crossover behaviour at least for a fraction of the probed molecules.

\section{Conclusions}

In conclusion, we investigated the influence of the surface in the formation of different crystal structures of a room temperature switchable spin crossover compound. We observed that when deposited on to a substrate, the surface induces the formation of two different crystal structures (possibly two different polymorphs), which exhibit opposite spin states below the transition temperature. This behaviour is not controllable in drop-casting configuration and seems to be independent of the solvent composition and shrinking rate.

Considering the DFT calculations, this difference was ascribed to the absence of water or polar solvent molecules in the structure. This work proves for the first time that the surface can induce the formation of particular crystal structures in spin crossover compounds with a dramatic effect on the properties. Usually this effect is considered a drawback for conventional applications; however the irreversibility of the system can be exploited to our advantage for specific applications such as time temperature integrators and sensing.

\section{Experimental}

\subsection{Materials}

The synthesis and purification of $\mathbf{1}$ are reported in ref. 51 . 
Thin deposits of 1 have been obtained from a $\mathrm{CH}_{3} \mathrm{OH}$ : $\mathrm{CH}_{2} \mathrm{Cl}_{2} 1: 1$ solution by drop-casting and slow evaporation on Si wafers. Spectroscopic grade quality solvents were purchased from Sigma Aldrich.

Dried crystals of SCO complex 1 (average size $0.05 \times 0.02 \times$ $0.02 \mathrm{~mm}^{3}$ ), suitable for single crystal diffraction experiments, have been obtained from thin deposits or by slow evaporation (average size $0.2 \times 0.08 \times 0.08 \mathrm{~mm}^{3}$ ) at $4{ }^{\circ} \mathrm{C}$ til dryness.

Substrate cleaning and preparation: silicon wafers $(1 \times$ $1 \mathrm{~cm}^{2}$ ) with native or thermally grown silicon dioxide layers (200 nm thick) were used as substrates. All substrates were cleaned by sonication in acetone for $10 \mathrm{~min}$ and then in 2-propanol for $10 \mathrm{~min}$, and dried in a stream of nitrogen prior to use.

\subsection{Calculation of Raman spectra}

Density functional theory (DFT) calculations of the Raman spectra were performed by using the Gaussian 09 software program. ${ }^{64}$ The hybrid functional $\mathrm{PBE} 0^{65}$ was employed with the $6-31 \mathrm{G}^{* *}$ basis set, substituted by the spin-state-corrected $\mathrm{s} 6-31 \mathrm{G}^{*}$ (ref. 66) basis set in the case of $\mathrm{Fe}^{\mathrm{II}}$. The equilibrium geometries in vacuo of the singlet and quintuplet states were obtained using tight convergence criteria and requiring ultrafine grids during the optimization procedure, in order to obtain accurate values of the harmonic frequencies. For the sake of clarity, the calculated Raman spectra were adapted for a better comparison with the experimental counterparts following the method suggested by Riauba et al. ${ }^{67}$ The harmonic frequencies were scaled by a factor $a(\nu)$, which depends on the frequency itself, i.e. $a(\nu)=1-\left(1-a^{\mathrm{F}}\right)\left(\nu-\nu^{0}\right) /\left(\nu^{\mathrm{F}}-\nu^{0}\right)$ using the following parameters: $a^{\mathrm{F}}=0.90, \nu^{\mathrm{F}}=3000$, and $\nu^{0}=400$, which are adequate to nicely simulate both vibrational spectra. Moreover, the calculated Raman activities $\left(I_{\mathrm{R}}\right)$ were scaled, since they tend to have higher values at high frequency than those at low frequencies, therefore obscuring them. In this case, the proposed original formula was modified by subtracting the Euler's number to the natural logarithm of the frequency, i.e. $I_{\mathrm{R}}^{\prime}\left(\nu_{\mathrm{i}}\right)=I_{\mathrm{R}}\left(\nu_{\mathrm{i}}\right) /\left(\ln \left(\nu_{\mathrm{i}}\right)-e\right)$, and applied for $\nu_{\mathrm{i}} \geq$ $600 \mathrm{~cm}^{-1}$. Afterwards, the Raman spectra were simulated by a convolution of Gaussian functions with a full width at halfmaximum (FWHM) of $12 \mathrm{~cm}^{-1}$.

The LS and HS states of the organometallic complex were also investigated considering the X-ray geometry of $\mathbf{1}$ alone at $100 \mathrm{~K}$ and $300 \mathrm{~K}$ and with an added molecule of water using the same DFT method. The polarizable continuum model $(\mathrm{PCM})^{68}$ was adopted to study the relaxed structure of $\mathbf{1}$ in a $\mathrm{CH}_{3} \mathrm{OH}$ and $\mathrm{CH}_{2} \mathrm{Cl}_{2}$ solution. The charges were calculated by means of the natural population analysis ${ }^{60}$ by using the $\mathrm{NBO}^{59}$ program (version 3.1). The calculated geometries, Raman transitions and energies are reported in the ESI. $\dagger$

\subsection{Optical microscopy}

Optical micrographs were recorded with a Nikon i-80 microscope equipped with epi-illuminator and cross polars (POM). The images presented were recorded using objectives: LU Plan
ELWD $20 \times / 0.40$ and $50 \times / 0.55$ objectives. Images were recorded by using a commercial CCD (DIGITAL SIGHT DS-2MV).

\subsection{Raman spectroscopy}

The Nd-YAG excitation wavelength (532 nm) was used to obtain Raman spectra in the $100-2000 \mathrm{~cm}^{-1}$ range. Raman scattering measurements were recorded in backscattering configuration using a long working-distance 50× microscope objective with a laser power lower than $25 \mu \mathrm{W}$ to avoid photothermal effects. The samples were mounted in a liquid nitrogen Peltier heating-cooling stage to span the 150-400 K temperature range.

\subsection{Thermal treatment and temperature control}

The thermal treatments were performed under an optical microscope using a heating stage Linkham TMHS600 connected to a TP94 controller, with a control of $0.1^{\circ} \mathrm{C}$ using the setup described in ref. 69.

\subsection{X-ray diffraction data collection}

Data collection was performed for all these systems at the X-ray diffraction beamline (XRD1) of the Elettra Synchrotron, Trieste (Italy) ${ }^{70}$ equipped with a Pilatus $2 \mathrm{M}$ image plate detector. Complete datasets have been collected at a monochromatic wavelength of $0.800 \AA$ by the rotating crystal method. Crystals of $\mathbf{R}$ and $\mathbf{I}$ crystals were dipped in N-paratone, to limit the solvent exchange during data acquisition, and mounted on the goniometer head with a nylon loop. The diffraction datasets were collected at controlled temperatures, using a nitrogen stream supplied by an Oxford Cryostream 700 at $100 \mathrm{~K}$, below and above the spin transition temperature.

Crystals of $\mathbf{R}$ polymorph heated above $300 \mathrm{~K}$ (temperatures up to $330 \mathrm{~K}$ have been tested) did not show diffraction.

Data were indexed, integrated and scaled using XDS. ${ }^{71}$ The structures were solved by direct methods using Sir2014, ${ }^{72}$ Fourier analysed and refined by full-matrix least-squares based on $F^{2}$ implemented in SHELXL-2014. ${ }^{73}$ The Coot program has been used for modelling. ${ }^{74}$ In the final refinement, all nonhydrogen atoms with full occupancy were treated anisotropically and the hydrogen atoms were included at calculated positions with isotropic $U_{\text {factors }}=1.2 U_{\mathrm{eq}}$ or $U_{\text {factors }}=1.5 U_{\mathrm{eq}}$ for methyl groups.

XRD characterization of thin deposits. The crystal structure of thin deposits has been characterized by performing specular and off-specular scans and rocking curves by using a SmartLab-Rigaku diffractometer, equipped with a rotating anode $\left(\mathrm{Cu} \mathrm{K} \mathrm{K}_{\alpha} \lambda=1.54180 \AA\right.$ ) followed by a parabolic mirror, to collimate the incident beam, and a series of different slits (placed before and after the sample position). Off-specular scans were carried out by recording $2 \theta$ scans with the incident angle fixed at $0.8^{\circ}$

\subsection{X-ray absorption (XAS)}

The X-ray absorption spectra of the $\mathrm{FeL}_{2,3}$ edges were recorded in Total Electron Yield (TEY) mode at the Advanced Photoelectric-effect Experiments (APE) beamline of the Elettra Synchro- 
tron light source, in a temperature range of $240-330 \mathrm{~K}$ and a base vacuum of the order of $2 \times 10^{-10}$ millibar. $^{75}$ The incidence angle of the X-ray beam with respect to the surface was set at 45 degrees. The spectra were recorded with an energy resolution of about $0.1 \mathrm{eV}$ and normalized to the incident photon flux through the TEY signal of a gold mesh intercepting the beam.

\subsection{Magnetic characterization}

Magnetic measurements were performed on a MPMS SQUID-XL-5 magnetometer (Quantum Design). The high temperature dependence of the magnetic moment was recorded at $B=0.1 \mathrm{~T}$ as an external magnetic field and the experiment was carried out using a special heating setup (Sample space oven, Quantum Design). The high temperature sample holder consisted of a quartz glass tube and a Teflon filler and its very small diamagnetic contribution had negligible contribution to the overall magnetization, which was dominated by the sample. The diamagnetic corrections of the molar magnetic susceptibilities were applied using Pascal's constants.

\section{Acknowledgements}

This work has been supported by the national project N-CHEM, Flagship NANOMAX and by the Italian Ministry of Research through the project NFFA-MIUR. We acknowledge Slovak grant agencies (Slovakia: APVV-14-0078, APVV-14-0073 and VEGA 1/0522/14) and COST Action CM1305 (ECOSTBio) for the financial support.

\section{Notes and references}

1 A. J. Cruz-Cabeza and J. Bernstein, Chem. Rev., 2014, 114, 2170-2191.

2 D. Braga and F. Grepioni, Chem. Soc. Rev., 2000, 29, 229238.

3 B. Moulton and M. J. Zaworotko, Chem. Rev., 2001, 101, 1629-1658.

4 A. Nangia, Acc. Chem. Res., 2008, 41, 595-604.

5 J. Tao, R. J. Wei, R. B. Huang and L. S. Zheng, Chem. Soc. Rev., 2012, 41, 703-737.

6 F. Di Maria, P. Olivelli, M. Gazzano, A. Zanelli, M. Biasiucci, G. Gigli, D. Gentili, P. D'Angelo, M. Cavallini and G. Barbarella, J. Am. Chem. Soc., 2011, 133, 8654-8661.

7 L. Maini, F. Gallino, M. Zambianchi, M. Durso, M. Gazzano, K. Rubini, D. Gentili, I. Manet, M. Muccini, S. Toffanin, M. Cavallini and M. Melucci, Chem. Commun., 2015, 51, 2033-2035.

8 G. Agusti, C. Bartual, V. Martinez, F. J. Munoz-Lara, A. B. Gaspar, M. C. Munoz and J. A. Real, New J. Chem., 2009, 33, 1262-1267.
9 M. Buron-Le Cointe, J. Hebert, C. Balde, N. Moisan, L. Toupet, P. Guionneau, J. F. Letard, E. Freysz, H. Cailleau and E. Collet, Phys. Rev. B: Condens. Matter, 2012, 85, 064114.

10 E. Collet, M. L. Boillot, J. Hebert, N. Moisan, M. Servol, M. Lorenc, L. Toupet, M. Buron-Le Cointe, A. Tissot and J. Sainton, Acta Crystallogr., Sect. B: Struct. Sci., 2009, 65, 474-480.

11 C. Faulmann, P. A. Szilagyi, K. Jacob, J. Chahine and L. Valade, New J. Chem., 2009, 33, 1268-1276.

12 A. Galet, A. B. Gaspar, M. C. Munoz, G. Levchenko and J. A. Real, Inorg. Chem., 2006, 45, 9670-9679.

13 M. Marchivie, P. Guionneau, J. F. Letard and D. Chasseau, Acta Crystallogr., Sect. B: Struct. Sci., 2003, 59, 479486.

14 G. S. Matouzenko, A. Bousseksou, S. Lecocq, P. J. van Koningsbruggen, M. Perrin, O. Kahn and A. Collet, Inorg. Chem., 1997, 36, 5869-5879.

15 R. Pritchard, H. Lazar, S. A. Barrett, C. A. Kilner, S. Asthana, C. Carbonera, J. F. Letard and M. A. Halcrow, Dalton Trans., 2009, 6656-6666.

16 D. L. Reger, J. R. Gardinier, M. D. Smith, A. M. Shahin, G. J. Long, L. Rebbouh and F. Grandjean, Inorg. Chem., 2005, 44, 1852-1866.

17 I. Salitros, O. Fuhr, A. Eichhofer, R. Kruk, J. Pavlik, L. Dlhan, R. Boca and M. Ruben, Dalton Trans., 2012, 41, 5163-5171.

18 C. F. Sheu, S. Pillet, Y. C. Lin, S. M. Chen, I. J. Hsu, C. Lecomte and Y. Wang, Inorg. Chem., 2008, 47, 1086610874

19 Z. Yan, M. Li, H. L. Gao, X. C. Huang and D. Li, Chem. Commun., 2012, 48, 3960-3962.

20 S. Q. Zang, X. M. Ren, Y. Su, Y. Song, W. J. Tong, Z. P. Ni, H. H. Zhao, S. Gao and Q. J. Meng, Inorg. Chem., 2009, 48, 9623-9630.

21 D. Gentili, M. Durso, C. Bettini, I. Manet, M. Gazzano, R. Capelli, M. Muccini, M. Melucci and M. Cavallini, Sci. Rep., 2013, 3, 2581.

22 M. Cavallini and M. Melucci, ACS Appl. Mater. Interfaces, 2015, 7, 16897-16906.

23 M. Cavallini, J. Mater. Chem., 2009, 19, 6085-6092.

24 D. Gentili, F. Valle, C. Albonetti, F. Liscio and M. Cavallini, Acc. Chem. Res., 2014, 47, 2692-2699.

25 M. Cavallini, R. Lazzaroni, R. Zamboni, F. Biscarini, D. Timpel, F. Zerbetto, G. J. Clarkson and D. A. Leigh, J. Phys. Chem. B, 2001, 105, 10826-10830.

26 P. Leclere, M. Surin, R. Lazzaroni, A. F. M. Kilbinger, O. Henze, P. Jonkheijm, F. Biscarini, M. Cavallini, W. J. Feast, E. W. Meijer and A. Schenning, J. Mater. Chem., 2004, 14, 1959-1963.

27 O. Kahn and C. J. Martinez, Science, 1998, 279, 44-48.

28 E. Breuning, M. Ruben, J. M. Lehn, F. Renz, Y. Garcia, V. Ksenofontov, P. Gutlich, E. Wegelius and K. Rissanen, Angew. Chem., Int. Ed., 2000, 39, 2504.

29 P. Gutlich, Y. Garcia and H. A. Goodwin, Chem. Soc. Rev., 2000, 29, 419-427.

30 O. Sato, Acc. Chem. Res., 2003, 36, 692-700. 
31 B. Rösner, M. Milek, A. Witt, B. Gobaut, P. Torelli, R. H. Fink and M. M. Khusniyarov, Angew. Chem., Int. Ed., 2015, 54, 12976-12980.

32 A. Bousseksou, G. Molnar, P. Demont and J. Menegotto, J. Mater. Chem., 2003, 13, 2069-2071.

33 F. Varret, K. Boukheddaden, E. Codjovi and A. Goujon, Hyperfine Interact., 2005, 165, 37-47.

34 A. Akou, I. y. A. Gural'skiy, L. Salmon, C. Bartual-Murgui, C. Thibault, C. Vieu, G. Molnar and A. Bousseksou, J. Mater. Chem., 2012, 22, 3752-3757.

35 M. Cavallini, Phys. Chem. Chem. Phys., 2012, 14, 1186711876.

36 M. Cavallini, D. Gentili, P. Greco, F. Valle and F. Biscarini, Nat. Protoc., 2012, 7, 1668-1676.

37 M. Cavallini, I. Bergenti, S. Milita, J. C. Kengne, D. Gentili, G. Ruani, I. Salitros, V. Meded and M. Ruben, Langmuir, 2011, 27, 4076-4081.

38 D. Gentili and M. Cavallini, Coord. Chem. Rev., 2013, 257, 2456-2467.

39 F. Prins, M. Monrabal-Capilla, E. A. Osorio, E. Coronado and H. S. J. van der Zant, Adv. Mater., 2011, 23, 15451549.

40 E. Coronado, C. Marti-Gastaldo, J. R. Galan-Mascaros and M. Cavallini, J. Am. Chem. Soc., 2010, 132, 5456-5468.

41 V. Meded, A. Bagrets, K. Fink, R. Chandrasekar, M. Ruben, F. Evers, A. Bernand-Mantel, J. S. Seldenthuis, A. Beukman and H. S. J. van der Zant, Phys. Rev. B: Condens. Matter, 2011, 83, 245415.

42 H. J. Shepherd, I. y. A. Gural'skiy, C. M. Quintero, S. Tricard, L. Salmon, G. Molnár and A. Bousseksou, Nat. Commun., 2013, 4, 3607.

43 D. Gentili, N. Demitri, B. Schafer, F. Liscio, I. Bergenti, G. Ruani, M. Ruben and M. Cavallini, J. Mater. Chem. C, 2015, 3, 7836-7844.

44 A. Bousseksou, G. Molnar, L. Salmon and W. Nicolazzi, Chem. Soc. Rev., 2011, 40, 3313-3335.

45 A. D. Naik, K. Robeyns, C. F. Meunier, A. F. Leonard, A. Rotaru, B. Tinant, Y. Filinchuk, B. L. Su and Y. Garcia, Inorg. Chem., 2014, 53, 1263-1265.

46 J. Linares, E. Codjovi and Y. Garcia, Sensors, 2012, 12, 4479-4492.

47 A. B. Gaspar and M. Seredyuk, Coord. Chem. Rev., 2014, 268, 41-58.

48 M. A. Halcrow, Chem. Soc. Rev., 2011, 40, 4119-4142.

49 M. A. Halcrow, Chem. Lett., 2014, 43, 1178-1188.

50 M. Nihei, T. Shiga, Y. Maeda and H. Oshio, Coord. Chem. Rev., 2007, 251, 2606-2621.

51 B. Schafer, C. Rajnak, I. Salitros, O. Fuhr, D. Klar, C. Schmitz-Antoniak, E. Weschke, H. Wende and M. Ruben, Chem. Commun., 2013, 49, 10986-10988.

52 J. A. Wolny, R. Diller and V. Schuenemann, Eur. J. Inorg. Chem., 2012, 2012, 2635-2648.

53 Y. A. Tobon, L. Kabalan, S. Bonhommeau, N. Daro, A. Grosjean, P. Guionneau, S. Matar, J.-F. Letard and F. Guillaume, Phys. Chem. Chem. Phys., 2013, 15, 1812818137.
54 M. M. Dirtu, F. Schmit, A. D. Naik, I. Rusu, A. Rotaru, S. Rackwitz, J. A. Wolny, V. Schuenemann, L. Spinu and Y. Garcia, Chem. - Eur. J., 2015, 21, 5843-5855.

55 A. Droghetti, D. Alfè and S. Sanvito, J. Chem. Phys., 2012, 137, 124303.

56 Y. Zhang, J. Chem. Phys., 2014, 141, 214703.

57 N. A. Tuan, J. Appl. Phys., 2012, 111, 07 D101.

58 A. Rudavskyi, C. Sousa, C. de Graaf, R. W. A. Havenith and R. Broer, J. Chem. Phys., 2014, 140, 184318.

59 J. P. Foster and F. Weinhold, J. Am. Chem. Soc., 1980, 102, 7211-7218.

60 A. E. Reed, R. B. Weinstock and F. Weinhold, J. Chem. Phys., 1985, 83, 735-746.

61 F. de Groot and A. Kotani, in Core Level Spectroscopy of Solids, CRC Press, 2008, ch. 6, pp. 225-285.

62 J.-J. Lee, H.-s. Sheu, C.-R. Lee, J.-M. Chen, J.-F. Lee, C.-C. Wang, C.-H. Huang and Y. Wang, J. Am. Chem. Soc., 2000, 122, 5742-5747.

63 B. Warner, J. C. Oberg, T. G. Gill, F. El Hallak, C. F. Hirjibehedin, M. Serri, S. Heutz, M.-A. Arrio, P. Sainctavit, M. Mannini, G. Poneti, R. Sessoli and P. Rosa, J. Phys. Chem. Lett., 2013, 4, 1546-1552.

64 M. J. Frisch, G. W. Trucks, H. B. Schlegel, G. E. Scuseria, M. A. Robb, J. R. Cheeseman, G. Scalmani, V. Barone, B. Mennucci, G. A. Petersson, H. Nakatsuji, M. Caricato, X. Li, H. P. Hratchian, A. F. Izmaylov, J. Bloino, G. Zheng, J. L. Sonnenberg, M. Hada, M. Ehara, K. Toyota, R. Fukuda, J. Hasegawa, M. Ishida, T. Nakajima, Y. Honda, O. Kitao, H. Nakai, T. Vreven, J. A. Montgomery Jr., J. E. Peralta, F. Ogliaro, M. J. Bearpark, J. Heyd, E. N. Brothers, K. N. Kudin, V. N. Staroverov, R. Kobayashi, J. Normand, K. Raghavachari, A. P. Rendell, J. C. Burant, S. S. Iyengar, J. Tomasi, M. Cossi, N. Rega, N. J. Millam, M. Klene, J. E. Knox, J. B. Cross, V. Bakken, C. Adamo, J. Jaramillo, R. Gomperts, R. E. Stratmann, O. Yazyev, A. J. Austin, R. Cammi, C. Pomelli, J. W. Ochterski, R. L. Martin, K. Morokuma, V. G. Zakrzewski, G. A. Voth, P. Salvador, J. J. Dannenberg, S. Dapprich, A. D. Daniels, O. Farkas, J. B. Foresman, J. V. Ortiz, J. Cioslowski and D. J. Fox, Gaussian, Inc., Wallingford, CT, USA, 2009.

65 C. Adamo and V. Barone, J. Chem. Phys., 1999, 110, 61586170.

66 M. Swart, M. Guell, J. M. Luis and M. Sola, J. Phys. Chem. A, 2010, 114, 7191-7197.

67 L. Riauba, G. Niaura, O. Eicher-Lorka and E. Butkus, J. Phys. Chem. A, 2006, 110, 13394-13404.

68 J. Tomasi, B. Mennucci and R. Cammi, Chem. Rev., 2005, 105, 2999-3094.

69 A. Calo, P. Stoliar, M. Cavallini, Y. H. Geerts and F. Biscarini, Rev. Sci. Instrum., 2010, 81, 033907.

70 A. Lausi, M. Polentarutti, S. Onesti, J. R. Plaisier, E. Busetto, G. Bais, L. Barba, A. Cassetta, G. Campi, D. Lamba, A. Pifferi, S. C. Mande, D. D. Sarma, S. M. Sharma and G. Paolucci, Eur. Phys. J. Plus, 2015, 130, 1-8.

71 W. Kabsch, Acta Crystallogr., Sect. D: Biol. Crystallogr., 2010, 66, 125-132. 
72 M. C. Burla, R. Caliandro, B. Carrozzini, G. L. Cascarano, C. Cuocci, C. Giacovazzo, M. Mallamo, A. Mazzone and G. Polidori, J. Appl. Crystallogr., 2015, 48, 306-309.

73 G. Sheldrick, Acta Crystallogr., Sect. A: Fundam. Crystallogr., 2008, 64, 112-122.

74 P. Emsley and K. Cowtan, Acta Crystallogr., Sect. D: Biol. Crystallogr., 2004, 60, 2126-2132.
75 G. Panaccione, I. Vobornik, J. Fujii, D. Krizmancic, E. Annese, L. Giovanelli, F. Maccherozzi, F. Salvador, A. De Luisa, D. Benedetti, A. Gruden, P. Bertoch, F. Polack, D. Cocco, G. Sostero, B. Diviacco, M. Hochstrasser, U. Maier, D. Pescia, C. H. Back, T. Greber, J. Osterwalder, M. Galaktionov, M. Sancrotti and G. Rossi, Rev. Sci. Instrum., 2009, 80, 043105. 